International Review of Research in Open and Distributed Learning Volume 20, Number 1

February - 2019

\title{
Structural Relationships of Factors Which Impact on Learner Achievement in Online Learning Environment
}

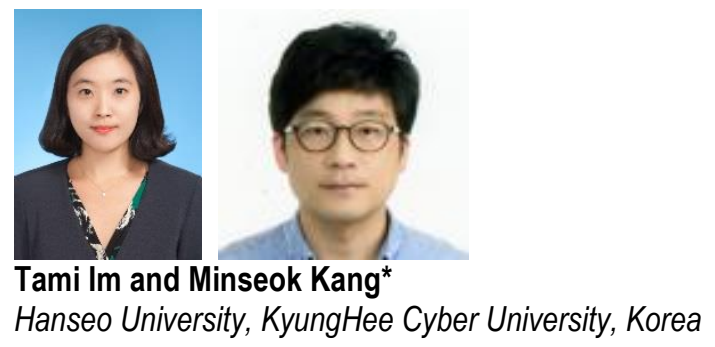

\begin{abstract}
The purpose of this study is to identify relationships of learners' achievement goal orientation, selfregulation, test-anxiety, self-efficacy, participation, satisfaction, and achievement in online learning environments in Korea. A total of 1,832 student responses from a Korean cyber university were used to find structural relationships of factors. Causal relationships among various variables are provided as results of this study. Achievement goal orientation -approach, self-regulated learning, test-anxiety, and self-efficacy, were positively related to participation; however, achievement goal orientation-avoidance was negatively related to participation. Test-anxiety was directly related to learning achievement and it was found that participation affected learning satisfaction and learning achievement. It was also revealed that learning satisfaction was related to learning achievement. Results of this study suggest that a comprehensive management of learners' psychological variables, such as achievement goal orientation, self-regulation, test-anxiety, self-efficacy for designing, and managing online learning environments is important to online learning organizations, instructors, and administrators for better learner support.
\end{abstract}

Keywords: online learning, achievement goal orientation, self-regulation, test-anxiety, self-efficacy, participation, satisfaction, achievement, structural relationships 


\section{Introduction}

With the rapid growth of MOOCs and smartphone technology, many people have developed an increased interest in online learning and choose it for their professional development or degree acquisition. MOOCs have changed the framework of formal education in many ways; learners are able to search and select courses that they want to attend, and they have flexibility of time and type of course delivery (Kaplan \& Haenlein, 2016). However, this autonomy comes with a heavy responsibility to learners. Learners in online courses, not only in MOOCs, are expected to have self-regulation skill since they are expected to engage in a learning process comparable to one in a traditional education setting (Puzziferro, 2008).

Mobile technology is another important factor that recently expanded online learning venues. Nowadays, a learners' daily life is prominently attached to mobile technology, creating a culture that manages almost everything through mobile devices. Mobile technology enables learning on-the-go as well as active learning through the exchange of learning materials based on various contexts (Jones, Scanlon, \& Clough, 2013; Shin \&Kang, 2016).

Given the different dynamics of learning in an online environment, many researchers explored diverse factors which impact on learning outcomes in this specific environment and investigate the relationships between various factors. Relationships between human-related variables and design variables (Piccoli, Ahmad, \& Ives, 2001); environment, individuals, and learning outcomes (Lim, Kang, \& Park, 2016); and interaction-related factors and learning outcomes Kang \& Im, 2013) have been examined in the online learning environment.

More specifically, learners' achievement goal orientation has been suggested as one of the important factors that predict learning achievement (Lee, 2003), and has shown a positive relationship with learning flow (Park \& Han, 2013). Self-regulated learning has been suggested as one of the predictive factors to learning satisfaction and learning achievement (Joo, Chung, Seol, \& Yi, 2012). Test-anxiety was studied as one of the critical factors that impact learning achievement, but the results were not consistent (Bak \& Im, 2010; Sung, Chao, \& Tseng, 2016). Also, studies that explore relationships among test-anxiety and other factors in the online learning environment are very limited. Self-efficacy has an important role in deciding how much effort learners will put into learning, so it is suggested to have a positive relationship with learning achievement (Zimmerman, Bandura, \& Martinez-Pons, 1992; Womble, 2007; Cho, 2010; Lim, Kang, and Park, 2016). In sum, the relationships between these factors and learning outcomes, such as participation, learning satisfaction, and learning achievement, were individually analyzed in previous studies. Thus, there is a lack of studies that explore comprehensive relationships of these factors with learning outcomes in online learning settings.

The purpose of this study is to identify determinants of learners' outcomes in online learning environments. Among various factors surrounding online learning, individual factors such as achievement goal orientation, self-regulated learning, test-anxiety, and self-efficacy were specifically selected for this study. Learning outcomes in this study represented learning satisfaction and learning achievement. 


\section{Background}

\section{Online Learning in Korea}

With the increased demands for flexible learning environments in Korea, coupled with the quality advancements in technology, online learning has increased. Usage of online learning in Korea has been experiencing exponential growth annually, from 53.3\% in 2012 to $58.2 \%$ in 2015 (National IT Industry Promotion Agency, 2016). Mobile learning has more rapidly expanded due to the one-person onesmartphone culture in Korea; between the years 2011 and 2013, the number of people who had experienced mobile learning nearly doubled from $18.4 \%$ to $32.9 \%$. (National IT Industry Promotion Agency, 2015)

A recent study tested a theoretical model of successful mobile learning (Shin \& Kang, 2016). This study found online university learners have started accepting mobile technology and this acceptance was directly and indirectly related to learning achievement.

With the growth of online learners, there are lots of efforts to figure out key factors for the success of online learning. Lim, Kang, and Park (2016) explored relationships of online learning environments, learner characteristics, and learning outcomes. These researchers found that qualities of online learning content and system are significant determinants of learners' motivation and self-efficacy. Also, learners' intrinsic and extrinsic motivation showed direct influence to their satisfaction but not to achievement in this study.

\section{Individual Variables Which Impact on Learning Outcomes}

Achievement goal orientation. Achievement goal orientation can be defined as a personal intent that affects the individual learner's decision of why and how to approach and participate in specific learning activities (Pintrich, 2000). Individual learners approach, participate, and respond to learning activities differently, and based on their achievement goal orientation (Ames, 1992). Achievement goal orientation focuses on how individual learners think about their motivation and intent to learn tasks apart from presence and absence of external learning motivation. Therefore, achievement goal orientation has been previously used as a framework that explains a learner's achievement motivation (McGregor \& Elliot, 2002).

Many of achievement goal orientation studies focused on examining the relationship with self-regulation strategies and achievement. Lee (2003) found learning achievement goal orientation was the most important factor that predicts the use of self-regulation strategy and learning outcome for undergraduate students. An experimental study showed goal orientation and motivation had significant correlations with learning flow in an online learning environment (Park \& Han, 2013) and Sen (2016) discovered performance approach goals and self-regulated learning skills were positively related to chemistry achievement.

Self-regulated learning. Prior research has found that self-regulated learning and learners' outcomes showed positive relationships (Cellar et al., 2011; Yukselturk \& Bulut, 2007; Sen, 2016). Positive relationship between self-regulated learning and achievement was found with college students in Korea 
(Lee \& Shin, 2013). Joo, Lee, and Hong (2011) revealed the positive effect of self-regulated learning to achievement within 317 cyber university students. It was also found that self-regulated learning positively predicted both satisfaction and achievement in an online learning environment (Joo, Chung, Seol, \& Yi, 2012), while Kang and Lim (2013) found that self-regulated learning directly affected achievement at Cyber University.

Test-anxiety. Test-anxiety refers to a response of anxiety when a person faces test situations (Mandler \& Sarason, 1952; Zeidner, 1998). Morris, Davis, and Hutchings (1981) conceptualized test anxiety consisting of two dimensions: cognitive dimension and affective dimension cognitive dimension of test-anxiety is called as worry, and affective dimension of test-anxiety is called as emotionality. Cognitive dimension of test anxiety refers to negative expectancy on doing well in certain test and affective dimension of test anxiety is about being nervous or terrified toward test. Previous studies show inconsistent results on the correlation between test-anxiety and learning outcomes (Chapell et al., 2005; Bak \& Im, 2010; Eum \& Rice, 2011; Sung et al., 20016).

A meta-analysis study found negative relationship between test-anxiety and achievement (Bak \& Im, 2010), whereas Sung et al. (2016) examined the relationship between test-anxiety and achievement and found positive correlation between them.

Self-efficacy. Self-efficacy refers to a personal judgment of one's own capability to perform activities that are necessary to succeed in certain tasks (Bandura, 1997). Self-efficacy possesses the critical role to determine that a person will put how much effort, and how long the efforts will last for the task (Zimmerman, 2000). Self-efficacy has been found to have positive relationships with learning outcomes in many studies (Zimmerman et al., 1992; Womble, 2007; Cho, 2010; Lim, Kang, \& Park, 2016). A metaanalysis study using publications in Korea between 2001 and 2014 revealed the mean effect size of selfefficacy to achievement as .66 (Ku, Yang, \& Choi 2014).

\section{Learning Outcomes}

Most important and commonly measured variables as learning outcomes are learners' satisfaction and achievement. Prior research suggested that both cognitive (achievement) and affective (satisfaction) dimensions of learning outcomes should be considered (Paechter, Maier, \& Macher, 2010; Lim, Kang, \& Park, 2016). In addition, satisfaction is known as one of the important factors for online course completion and achievement (Levy, 2007; Puzziferro, 2008; Wang, Shannon, \& Ross, 2013). It is possible to conclude that online learning success can be determined by how satisfied learners are with their online learning experience and level of achievement as a result.

Based on the review of related research, this study focuses on identifying determinants of learner satisfaction and achievement in an online learning environment. Among various factors surrounding online learning, individual factors including achievement goal orientation, self-regulated learning, testanxiety, and self-efficacy were specifically selected in this study. The research hypotheses with these given variables are like below: 
1. Learner's achievement goal orientation is related to satisfaction and achievement.

2. Learner's self-regulated learning skill is related to satisfaction and achievement.

3. Learner's test-anxiety is related to satisfaction and achievement.

4. Learner's self-efficacy is related to satisfaction and achievement.

\section{Methods}

\section{Participants}

Participants of this study were undergraduate students in a cyber university in Korea. Originally, a survey was sent to 2,224 students, however, 392 invalid responses (empty or identical responses) were excluded from the analysis. Thus, 1,832 questionnaires were used in addressing the study's research questions. Demographic information of survey participants is shown in Table 1.

Table 1

Participant Demographics

\begin{tabular}{llllll}
\hline \multicolumn{2}{c}{ Gender } & \multicolumn{2}{c}{ Age } & Grade \\
\hline Category & Number & Category & Number & Category & Number \\
\hline Male & 855 & Under 19 & 8 & 1 & 990 \\
Female & 977 & $20 \sim 29$ & 457 & 2 & 769 \\
& & $30 \sim 39$ & 504 & 3 & 274 \\
& & $40 \sim 49$ & 597 & 4 & \\
Total & \multirow{2}{*}{1,832} & Over 50 & 266 & & 1,832 \\
\hline
\end{tabular}

\section{Materials}

A questionnaire was developed for this study based on previous studies regarding achievement goal orientation, self-regulated learning, test-anxiety, self-efficacy, participation, learning satisfaction, and learning achievement. In this study, achievement goal orientation was measured by two dimensions including approach and avoidance. Three experts in educational measurement and educational technology reviewed this questionnaire for ensuring face validity. 
To measure learner's achievement goal orientation, 16 items regarding achievement goal orientation approach, and 10 items regarding achievement goal orientation approach were adopted from a survey by Bak and Lee (2005) with a Cronbach's $\alpha$ of .88 and .86 respectively. Fifteen items were adopted from a research of Pintrich and De Groot (1990) to measure learner's self-regulated learning and the Cronbach's $\alpha$ for these items was .90. Regarding test-anxiety 10 items were adopted from a questionnaire designed by Spielberger et al. (1980) with a Cronbach's $\alpha$ of .95. For checking self-efficacy of learners, nine items were adopted from Lee (2006) and Flowers (2011), with a Cronbach's a of .95. Each item consisted of a 5-point Likert scale from 1 = strongly disagree, 2 = disagree, $3=$ neutral, $4=$ agree, to $5=$ strongly agree. Number of survey items and Cronbach's $\alpha$ for each variable are shown in Table 2.

Table 2

Number of Survey Items

\begin{tabular}{lll}
\hline Category & Number of items & Cronbach's $\alpha$ \\
\hline Achievement goal orientation_approach & 16 & .88 \\
Achievement goal orientation_avoidance & 10 & .86 \\
Self-regulated learning & 15 & .90 \\
Test-anxiety & 20 & .95 \\
Self-efficacy & 9 & .95 \\
Participation & 16 & .91 \\
Learning satisfaction & 3 & .90 \\
Learning achievement & 6 & .94 \\
\hline
\end{tabular}

\section{Data Collection}

A total of 1,832 survey responses were collected for 10 days using the university's online learning platform. Structural equation modeling was used to investigate the research model hypotheses, and the data was analyzed using AMOS 18.0.

\section{Results}

\section{Measurement Model}

Convergent validity. Before analyzing convergent validity, an exploratory factor analysis was done and valid factors were extracted. A convergent validity test (Fornell \& Larcker, 1981) was conducted in three elements: item reliability, construct's composite reliability, and the average variance extracted (AVE). Item reliability test was conducted to confirm convergent validity of items with factor loading of each item. The factor loadings for the items were ranged between .697 .934, which were significant and met the convergent reliability. Composite reliability met the required value of $\geq .7(.764 \sim .963)$, AVE met 
the required value of $\geq .5(.503 \sim .868)$. The fit indices were obtained as follows: $x^{\wedge} 2 / \mathrm{df}=5.923$; TLI $=.964 ; \mathrm{CFI}=.976 ; \mathrm{RMSEA}=.052$.

Discriminant validity. A construct's discriminant validity test was performed. The square root of the AVE should exceeds the correlation coefficient between constructs to obtain the validity (Segars \& Grover, 1998). Table 3 shows the results of the validity test and confirms the research instrument's validity.

Table 3

Correlation Matrices and Discriminant Validity Among Variables

\begin{tabular}{|c|c|c|c|c|c|c|c|c|c|}
\hline Variable ${ }^{* *}$ & AVE & $\begin{array}{c}\text { AGO- } \\
\text { AP }\end{array}$ & $\begin{array}{c}\text { AGO- } \\
\text { AV }\end{array}$ & SRL & TA & $\mathrm{SE}$ & $\mathrm{PA}$ & $\mathrm{LS}$ & LA \\
\hline AGO-AP & .61 & $.84^{*}$ & & & & & & & \\
\hline AGO-AV & .50 & -.03 & $.78^{*}$ & & & & & & \\
\hline SRL & .76 & .55 & -.31 & $.71^{*}$ & & & & & \\
\hline TA & .71 & .07 & .43 & -.11 & $.87^{*}$ & & & & \\
\hline $\mathrm{SE}$ & .50 & .44 & -.06 & .55 & -.11 & $.71^{*}$ & & & \\
\hline $\mathrm{PA}$ & .69 & .51 & -.34 & .75 & -.16 & .55 & $.83^{*}$ & & \\
\hline LS & .75 & .39 & -.27 & .57 & -.05 & .36 & .58 & $.87^{*}$ & \\
\hline $\mathrm{LA}$ & .87 & .43 & -.25 & .37 & -.03 & .37 & .60 & .93 & \\
\hline
\end{tabular}

${ }^{*}$ Square root of the AVE (Average Variance Extracted) ${ }^{* *}$ AGO_AP : Achievement Goal Orientation related to APproach, AGO_AV : Achievement Goal Orientation related to AVoidance, SRL : Self-Regulated Learning, TA : Test Anxiety, SE : Self Efficacy, PA : Participation, LS : Learning Satisfaction, LA : Learning Achievement.

Structural model. Indices for the structural model indicated that the model was adequate. The following results were obtained: $\left(\mathrm{x}^{\wedge} 2\right)=758.443(\mathrm{p}<.001) ; \mathrm{x}^{\wedge} 2 / \mathrm{df}=6.116$; TLI = .963; CFI = .973; RMSEA $=.053$.

Figure 1 shows causal relationships among variables. Detailed results are as follows: AGO_AP was not related to PA, but AGO_AV related to PA. SRL, TA, and SE were related to PA. TA was related to LA. PA was related to LS and LA. LS was related to LA. 


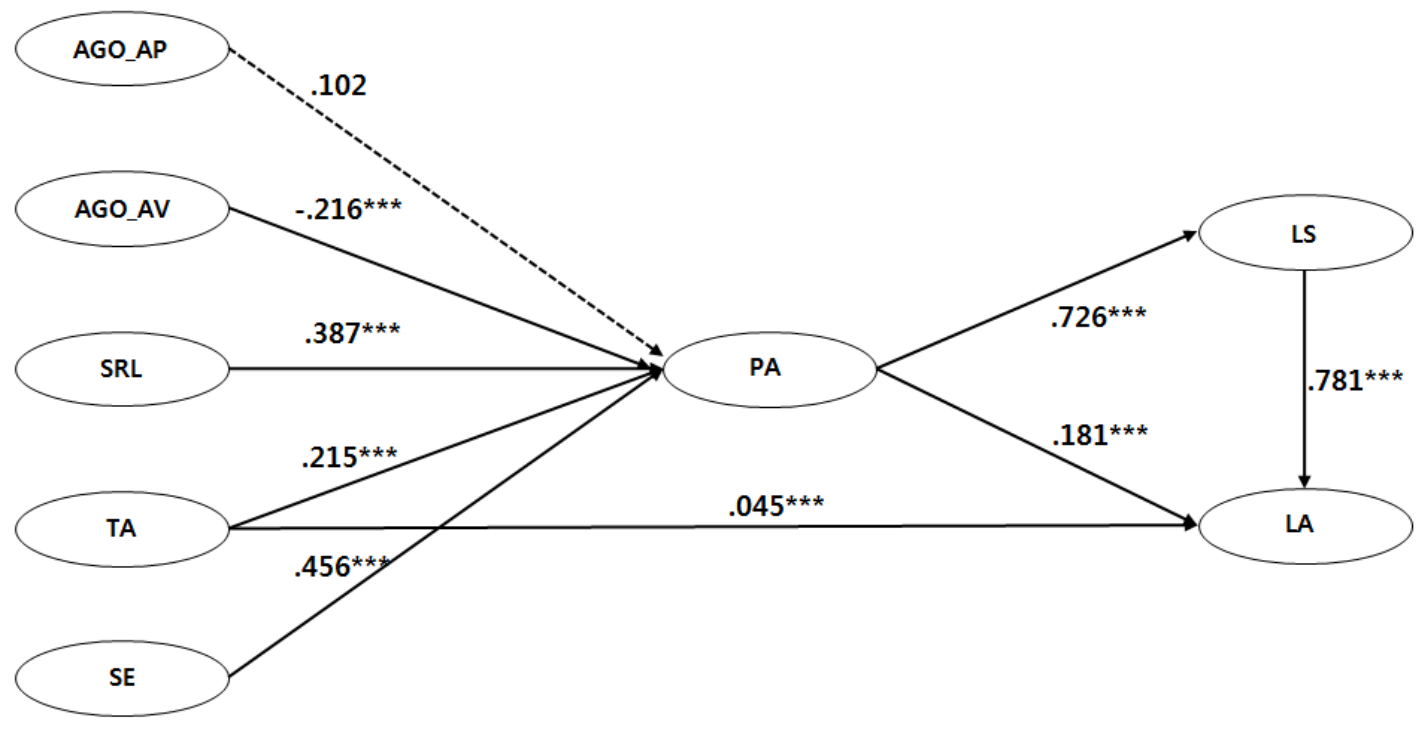

Figure 1. Structural relationships between variables. AGO_AP : Achievement Goal Orientation related to APproach, AGO_AV : Achievement Goal Orientation related to AVoidance, SRL : Self-Regulated Learning, TA : Test Anxiety, SE : Self Efficacy, PA : Participation, LS : Learning Satisfaction, LA : Learning Achievement.

Indirect and total effects for the research model are provided in Table 4. First, self-efficacy was the most powerful determinant for participation, with a total effect of .46. This was followed by self-regulated learning, test-anxiety, with a total effect of .39 and .25 respectively. Second, participation was the most important determinant for learning satisfaction, with a total effect of .73 . This was followed by selfefficacy, self-regulated learning, test-anxiety, with a total effect of $.33, .28$, .and .18 respectively. Third, learning satisfaction was shown as the most influential determinant for learning achievement, with a total effect of .78. This was followed by participation, self-efficacy, self-regulated learning, and test-anxiety, with a total effect of $.75, .34, .29$, and .23 respectively. 
Table 4

Direct, Indirect, and Total Effects for the Research Model ( $A->B)$

\begin{tabular}{|c|c|c|c|c|c|c|c|c|c|}
\hline \multirow{2}{*}{$\begin{array}{l}\mathrm{B} \\
\mathrm{A}\end{array}$} & \multicolumn{3}{|l|}{$\mathrm{PA}$} & \multicolumn{3}{|l|}{$\mathrm{LS}$} & \multicolumn{3}{|l|}{ LA } \\
\hline & Direct & Indirect & Total & Direct & Indirect & Total & Direct & Indirect & Total \\
\hline AGO_AP & .10 & & .10 & & .07 & .07 & & .08 & .08 \\
\hline AGO_AV & $-.21^{*}$ & & $-.21^{*}$ & & $-.16^{*}$ & $-.16^{*}$ & & $-.16^{*}$ & $-.16^{*}$ \\
\hline SRL & $.39^{*}$ & & $.39^{*}$ & & $.28^{*}$ & $.28^{*}$ & & $.29^{*}$ & $.29^{*}$ \\
\hline $\mathrm{TA}$ & $.25^{*}$ & & $.25^{*}$ & & $.18^{*}$ & $.18^{*}$ & $.05^{*}$ & $.18^{*}$ & $.23^{*}$ \\
\hline SE & $.46^{*}$ & & $.46^{*}$ & & $.33^{*}$ & $.33^{*}$ & & $.34^{*}$ & $.34^{*}$ \\
\hline $\mathrm{PA}$ & & & & $.73^{*}$ & & $.73^{*}$ & $.18^{*}$ & $.57^{*}$ & $.75^{*}$ \\
\hline LS & & & & & & & $.78^{*}$ & & $.78^{*}$ \\
\hline
\end{tabular}

${ }^{*} p<.05$ AGO_AP : Achievement Goal Orientation related to APproach, AGO_AV : Achievement Goal Orientation related to AVoidance, SRL : Self-Regulated Learning, TA : Test Anxiety, SE : Self Efficacy, PA : Participation, LS : Learning Satisfaction, LA : Learning Achievement.

\section{Discussion and Conclusion}

In this study, structural relationships among learners' characteristics, participation, satisfaction, and achievement in the context of online learning environment were explored. As a result of this study, a model that achievement goal orientation, self-regulation, test-anxiety, self-efficacy have impact on learners' participation, and participation turned out valid. Specifically, this model showed that participation has a mediated effect among exogenous variables and achievement.

Summary of results of this study is like below. First, achievement goal avoidance was negatively related to participation, satisfaction, and achievement. Second, test-anxiety was positively related to participation, satisfaction, and achievement. Third, participation had a mediated effect between three of exogenous variables (self-regulated learning, test-anxiety, self-efficacy) and satisfaction and learning achievement. Fourth, participation had the biggest impact on satisfaction, as well as biggest impact on learning achievement mediated by satisfaction. One of interesting findings from this study is that test-anxiety showed positive relationships with participation, satisfaction, and achievement, which is different with main stream of previous studies. Most of text-anxiety research found negative relationship between testanxiety and achievement. However, few studies found positive relationship between test-anxiety and achievement (Sung et al., 2016; Hardy \& Hutchinson, 2007). These researchers suggested that testanxiety increased performance motivation and improved achievement as a result based on the motivational enhancement model. 
Here are two plausible reasons for this interesting result. First, the participants of this study were adult learners mostly had a full time job pursuing a bachelor's degree from the Cyber University. It means they had a clear goal to achieve and high responsibilities for their learning. Thus, for these learners, testanxiety made them more motivated to study hard and led to better achievement. Second, the unique test environment in the Cyber University may decrease the cognitive interference effect. The test environment in online learning could be more relaxing and less stressful.

Results of this study showed that learners' psychological variables as exogenous variables had strong impact on participation and learning achievement. This study examined the structural model that explained learners' achievement goal orientation, self-regulation, test-anxiety, self-efficacy had positive effects on learning outcomes (satisfaction, achievement) mediated by participation and it would be valuable for further research. Based on the results of study, it could be suggested that a comprehensive management of learners' psychological variables such as achievement goal orientation, self-regulation, test-anxiety, self-efficacy for designing and managing online learning environment is important to online learning organizations, instructors, and administrators for better support to learners. 


\section{References}

Ames, C. (1992). Classrooms: Goals, structures, and student motivation. Journal of Educational Psychology, 84(3), 261-271. https://doi.org/10.1037/o022-0663.84.3.261

Bak, B. G., \& Lee, J. U. (2005). Development and validation of a $2 \times 2$ achievement goal orientation scale. The Korean Journal of Educational Psychology, 19(1), 327-352. Retrieved from http://www.dbpia.co.kr/Journal/ArticleDetail/NODE06763545\#

Bak, B. G., \& Im, S. I. (2010). A meta-analysis of test anxiety with related variables. Korean Educational Psychology Association, 24(4), 875-894. Retrieved from http://www.dbpia.co.kr.oca.korea.ac.kr/Journal/ArticleDetail/NODEo6763822

Bandura, A. (1997). Self-efficacy: The exercise of control. New York: W.H. Freeman.

Cellar, D. F., Stuhlmacher, A. F., Young, S. K., Fisher, D. M., Adair, C. K., Haynes, S. ... Riester, D. (2010). Trait goal orientation, self-regulation, and performance: A Meta-analysis. Journal of Business and Psychology, 26(4), 467-483. https://doi.org/10.1007/s10869-010-9201-6

Chapell, M. S., Blanding, Z. B., Silverstein, M. E., Takahashi, M., Newman, B., Gubi, A., \& McCann, N. (2005). Test anxiety and academic performance in undergraduate and graduate students. Journal of Educational Psychology, 97(2), 268-274. https://doi.org/10.1037/0022-0663.97.2.268

Cho, H. I. (2010). The structural equation modeling analysis of self-efficacy, hope, and depression on academic achievement. The Journal of Child Education, 19(2), 259-271. Retrieved from http://kiss.kstudy.com.oca.korea.ac.kr/thesis/thesis-view.asp?key=2841621

Flowers, L. O. (2011). Exploring HBCU student academic self-efficacy in online STEM courses. The Journal of Human Resource and Adult Learning, 7(2), 139-145. Retrieved from http://connection.ebscohost.com/c/articles/91708910/exploring-hbcu-student-academic-selfefficacy-online-stem-courses

Fornell, C., \& Larcker, D. F. (1981). Evaluating structural equation models with unobservable variables and measurement error. Journal of Marketing Research, 18(1), 39. https://doi.org/10.2307/3151312

Hardy, L., \& Hutchinson, A. (2007). Effects of performance anxiety on effort and performance in rock climbing: A test of processing efficiency theory. Anxiety, Stress, \& Coping, 2o(2), 147-161. https://doi.org/10.1080/10615800701217035

Joo, Y. J., Chung, A. K., Seol, H. N., \& Yi, S. H. (2012). The prediction of mastery-approach goal orientation, task value, and self-regulated learning strategy on academic satisfaction and achievement of cyber engineering university students. Journal of The Institute of Electronics Engineering of Korea, 49-IE(2), 65-74. Retrieved from http://www.dbpia.co.kr.oca.korea.ac.kr/Journal/ArticleDetail/NODE01897075 
Joo, Y. J., Lee, S. Y., \& Hong, Y. N. (2011). The structural relationship among perceived instrumentality, mastery goal orientation, self-regulated learning, and academic achievement in cyber university. Journal of Korean Information Education, 15(4), 645-660. Retrieved from http://www.earticle.net.oca.korea.ac.kr/article.aspx?sn=163407

Jones, A. C., Scanlon, E., \& Clough, G. (2013). Mobile learning: Two case studies of supporting inquiry learning in informal and semiformal settings. Computers \& Education, 61, 21-32. https://doi.org/10.1016/j.compedu.2012.08.008

Kang, M., \& Im, T. . (2013). Factors of learner-instructor interaction which predict perceived learning outcomes in online learning environment. Journal of Computer Assisted Learning, 29(3), 292301. https://doi.org/10.1111/jcal.12005

Kang, M., \& Lim, K. (2013). Structural analyses on the effects of self-regulated learning and learning motivation on learner-instructor interactions and academic performance in college learning environments with e-learning contents. The Journal of the Korea Contents Association, 13(11), 1014-1023. https://doi.org/10.5392/JKCA.2013.13.11.1014

Kaplan, A. M., \& Haenlein, M. (2016). Higher education and the digital revolution: About MOOCs, SPOCs, social media, and the cookie monster. Business Horizons, 59(4), 441-450. https://doi.org/10.1016/j.bushor.2016.03.008

Ku, B. D., Yang, A. K., \& Choi, J. J. (2014). A meta-analysis on the effects of academic achievement in selfefficacy: Focused on theses and journal paper in Korea since 2000. Korean Journal of Counseling, 15(5), 1979-2000. Retrieved from http://kiss.kstudy.com.oca.korea.ac.kr/thesis/thesisview.asp?key $=3275189$

Lee, Y. H. (2003). Investigating the relationships among goal orientation, self-regulated learning strategies and academic achievement in online inquiry-based learning (Unpublished master's thesis). Ewha Womans University, Seoul. Retrieved from http://www.riss.kr.oca.korea.ac.kr

Lee, Y. C. (2006). An empirical investigation into factors influencing the adoption of an e-learning system. Online Information Review, 3o(5), 517-541. doi: 10.1108/14684520610706406

Lee, S. J., \& Shin, K. H. (2013). Effect of achievement goal directivity and self-regulated learning strategy on the level of learning achievement. Journal of Digital Convergence, 11(12), 829-834. https://doi.org/10.14400/JDPM.2013.11.12.829

Levy, Y. (2007). Comparing dropouts and persistence in e-learning courses. Computers \& Education, 48(2), 185-204. https://doi.org/10.1016/j.compedu.2004.12.004

Lim, K., Kang. M., \& Park, S. Y. (2016). Structural relationships of environments, individuals, and learning outcomes in Korean online university settings. The International Review of Research in Open and Distributed Learning, 17(4). http://dx.doi.org/10.19173/irrodl.v17i4.2500 
Mandler, G., \& Sarason, S. B. (1952). A study of anxiety and learning. The Journal of Abnormal and Social Psychology, 47(2), 166-173. https://doi.org/10.1037/hoo62855

McGregor, H. A., \& Elliot, A. J. (2002). Achievement goals as predictors of achievement-relevant processes prior to task engagement. Journal of Educational Psychology, 94(2), 381-395. https://doi.org/10.1037/0022-0663.94.2.381

Morris, L. W., Davis, M. A., \& Hutchings, C. H. (1981). Cognitive and emotional components of anxiety: Literature review and a revised worry-emotionality scale. Journal of Educational psychology, 73(4), 541. http://dx.doi.org/10.1037/0022-0663.73.4.541

National IT Industry Promotion Agency. (2015). 2013-2014 e-learning White Paper. Jincheon, North Chungcheong Province: Ministry of Trade, Industry \& Energy. Retrieved from http://www.iita.re.kr/board/boardView.it?boardNo $=79 \&$ contentNo $=54 \&$ menuNo $=294 \& g u b n=\&$ page $=1$ \&registDate $=$

National IT Industry Promotion Agency. (2016). 2015 Survey of Korean e-Learning Industry. Jincheon, North Chungcheong Province: Ministry of Trade, Industry \& Energy. Retrieved from https://www.nipa.kr/board/boardView.it

Paechter, M., Maier, B., \& Macher, D. (2010). Students' expectations of, and experiences in e-learning: Their relation to learning achievements and course satisfaction. Computers \& Education, 54(1), 222-229. https://doi.org/10.1016/j.compedu.2009.08.005

Park, I \& Han, I. (2013). The effects of goal orientation, motivation and self-concept on learning flow in adult learners. CNU Journal of Educational Studies, 1, 151-178.

Piccoli, G., Ahmad, R., \& Ives, B. (2001). Web-based virtual learning environments: A research framework and a preliminary assessment of effectiveness in basic IT skills training. MIS Quarterly, 25(4), 401. https://doi.org/10.2307/3250989

Pintrich, P. R. (2000). An achievement goal theory perspective on issues in motivation terminology, theory, and research. Contemporary Educational Psychology, 25(1), 92-104. https://doi.org/10.1006/ceps.1999.1017

Pintrich, P. R., \& De Groot, E. V. (1990). Motivational and self-regulated learning components of classroom academic performance. Journal of Educational Psychology, 82(1), 33. https://doi.org/10.1037//o022-0663.82.1.33

Puzziferro, M. (2008). Online technologies self-efficacy and self-regulated learning as predictors of final grade and satisfaction in college-level online courses. American Journal of Distance Education, 22(2), 72-89. https://doi.org/10.1080/08923640802039024

Segars, A. H., \& Grover, V. (1998). Strategic information systems planning success: An investigation of the construct and its measurement. MIS Quarterly, 22(2), 139. https://doi.org/10.2307/249393 
Şen, Ş. (2016). The relationship between secondary school students' self-regulated learning skills and Chemistry achievement. Journal of Baltic Science Education, 15(3), 312-324. Retrieved from http://www.scientiasocialis.lt/jbse/files/pdf/vol15/312-324.Sen JBSE Vol.15 No.3.pdf

Shin, W. S., \& Kang, M. (2016). The use of a mobile learning management system at an online university and its effect on learning satisfaction and achievement. The International Review of Research in Open and Distributed Learning, 16(3). http://dx.doi.org/10.19173/irrodl.v16i3.1984

Spielberger, C. D., Gonzalez, H. P., Taylor, C. J., Anton, W. D., Algaze, B., Ross, G. K., \& Westberry, L. G. (1980). Test anxiety inventory. Palo Alto. CA: Mind Garden, Inc.

Sung, Y.-T., Chao, T.-Y., \& Tseng, F.-L. (2016). Reexamining the relationship between test anxiety and learning achievement: An individual-differences perspective. Contemporary Educational Psychology, 46, 241-252. https://doi.org/10.1016/j.cedpsych.2016.07.001

Zeidner, M. (1998). Test anxiety: The state of the art. New York: Plenum Press.

Zimmerman, B. J., Bandura, A., \& Martinez-Pons, M. (1992). Self-motivation for academic attainment: The role of self-efficacy beliefs and personal goal setting. American Educational Research Journal, 29(3), 663-676. https://doi.org/10.3102/00028312029003663

Zimmerman, B. J. (2000). Self-efficacy: An essential motive to learn. Contemporary Educational Psychology, 25(1), 82-91. https://doi.org/10.1006/ceps.1999.1016

Wang, C.H., Shannon, D. M., \& Ross, M. E. (2013). Students' characteristics, self-regulated learning, technology self-efficacy, and course outcomes in online learning. Distance Education, 34(3), 302-323. https://doi.org/10.1080/01587919.2013.835779

Womble, J. C. (2007). E-learning: The relationship among learner satisfaction, self-efficacy, and usefulness (Doctoral dissertation). Retrieved from https://www.learntechlib.org/p/119496/

Yukselturk, E., \& Bulut, S. (2007). Predictors for student success in an online course. Journal of Educational Technology \& Society, 1O(2). Retrieved from https://www.jstor.org/stable/pdf/jeductechsoci.10.2.71.pdf?seq=1\#page scan tab content

\section{Athabasca University}

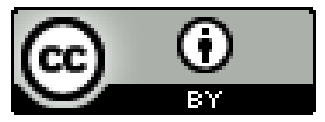

